\title{
CHANGE IN POLICY
}

To authors and readers:

Because of our extensive backlog of articles, the constant flow of new manuscript submissions, and your interest in a wide variety of topics, we must announce:

Church History will no longer consider for publication any article of more than 25 pages in length double-spaced, including footnotes. Left margins should measure one and onehalf inches.

The Editors 


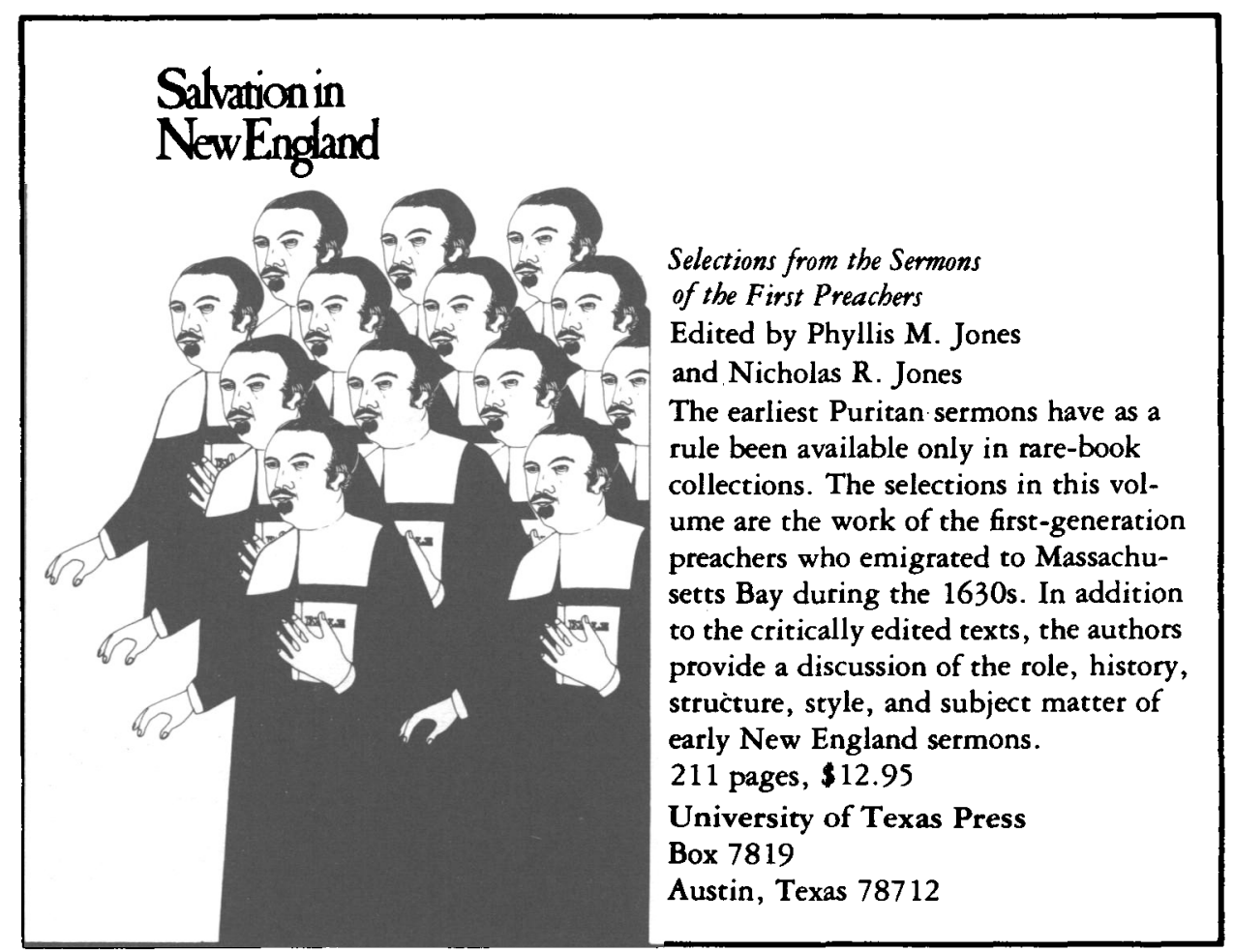




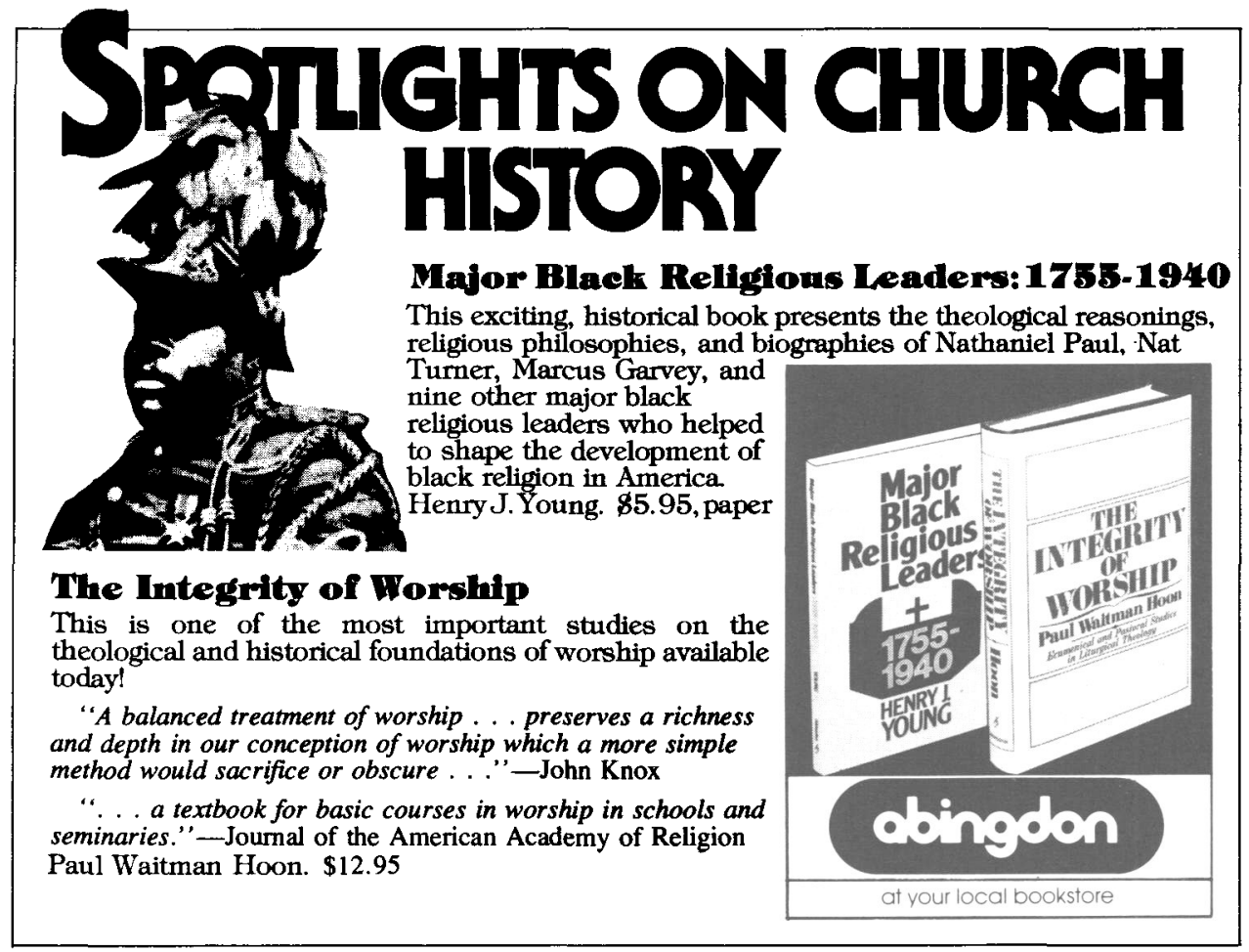

